\title{
Coagulation studies in massive pulmonary haemorrhage of the newborn
}

\author{
J. T. ROBERTS, A. J. DAVIES, AND A. L. BLOOM \\ From the Welsh National School of Medicine, Institute of Pathology, Royal Infirmary, Cardiff
}

SYNOPSIS Coagulation studies were performed on two newborn infants with fatal massiveo pulmonary haemorrhage. The first showed a reduced level of plasma fibrinogen with defective thrombin-fibrinogen reaction, corrected by protamine, and defective thromboplastin generation. In $\vec{\bullet}$ the second case, a premature infant, the fibrinogen level was normal but there was a severe defect: in thromboplastin generation with evidence of an inhibitor. A relationship between the pulmonary $\mathscr{\omega}^{\omega}$ haemorrhage and coagulation defects is suggested but not established.

The occurrence of massive pulmonary haemorrhage in the newborn is well recognized. In a classical case a child, who may previously have been well, rapidly becomes sick when about 3 days old, bleeds from the mouth and nose, and dies in a matter of hours. At necropsy the respiratory passages are filled with blood, the appearance suggesting 'that the infant drowns in its own blood' (Potter, 1961).

Ahvenainen and Call (1952) did not think that pulmonary haemorrhage was a separate distinct entity, and they noticed kernicterus, infection, overtransfusion, congenital heart disease, intracranial haemorrhage, and a prolonged prothrombin time as associated features. Claireaux (1958) and MacGregor (1960) both subscribe to the existence of massive pulmonary haemorrhage of obscure aetiology. Claireaux thought that in the mature child anoxic damage to the pulmonary capillaries might be responsible, and that infection was an unlikely cause. Often there is no bleeding at other sites.

Pulmonary haemorrhage of varying degree is a common finding at necropsy in neonates. Vejlens (1944) found a $10 \%$ incidence and Thorburn (1963) in Jamaica one of $8 \%$. Thorburn thought that inhalation of gastric contents might be responsible. In Singapore, Sivanesan (1961) found an incidence of $13 \%$ and that it occurred both with and without cerebral haemorrhage. Mann and Elliott (1957) found pulmonary haemorrhage in children dying of cold. Finally Butler and Bonham (1963) found an increased mortality from massive pulmonary haemorrhage in dysmature children, that is children who are below the expected weight for their gestational age.

In this paper we report coagulation studies on two Received for publication 17 January 1966. cases. Both showed massive pulmonary haemor rhage. The first was a post-mature child who pre- $\overrightarrow{0}$ sented with sudden illness. The blood showedo hypofibrinogenaemia with abnormalities of the thrombin-fibrinogen reaction. The second was a premature child, ill from birth, with hypoglycaemia and hypothermia, and finally massive bleeding. Cerebral haemorrhage was also present. The bloodo in this case showed a circulating inhibitor of thromboplastin generation.

CLINICAL FEATURES AND NECROPSY FINDINGS

CASE 1 This child was born to a 39-year-old gravida two blood group $A \mathrm{Rh}$ positive, with negative Wassermann? reaction. At the age of 17 she had an ovarian cystectomy and at the age of 34 she had a 21-month course of chemotherapy for pulmonary tuberculosis. At the same age sheO had a miscarriage when three months pregnant. Since that time she has suffered from chronic bronchitis. In hero second pregnancy because of unstable lie, together with obesity and mild hypertension $(130 / 85 \mathrm{~mm}$. $\mathrm{Hg})$, electiveO lower segment Caesarian section was performed when she was 18 days post-mature by dates. Operation wasos uneventful. She was given anticoagulants in the puer $\mathrm{N}$ perium for varicose leg veins. The placenta weighed $700 \mathrm{~g}$. and was recorded as being gritty with infarcts oncw both surfaces.

The child breathed within 30 seconds and gave neo initial cause for alarm. Routine pharyngeal suction wast performed but neither oxygen nor vitamin $\mathbf{K}$ were given Bottle feeds were taken well. Birth weight was 3,375 g.0 and blood group A Rh positive. The Coombs test waso negative.

When 3 days $15 \frac{1}{2}$ hours old he was found in his cot a 5.30 a.m. having convulsions. Temperature was $42^{\circ} \mathrm{C} \Omega$ and the skin was mottled. He started to bleed from the mouth and nose, but no rash or petechiae were present 8 


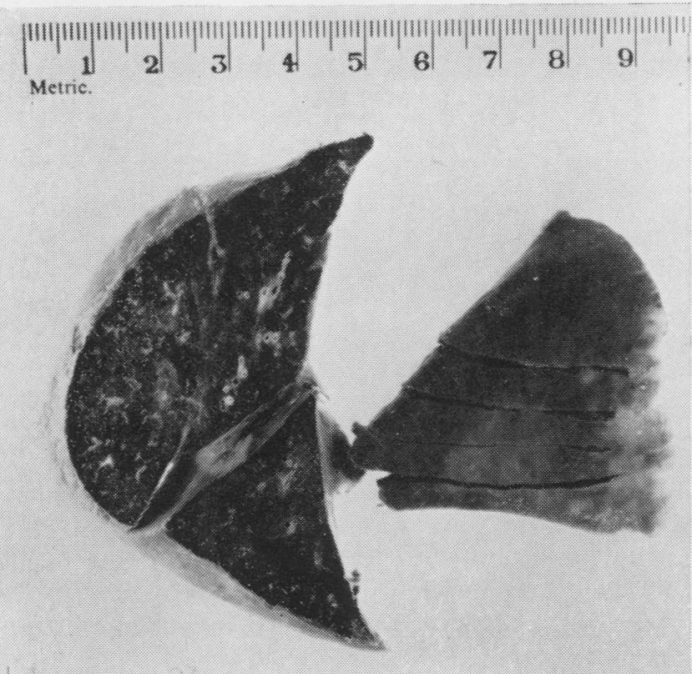

FIG. 1 Cut surface of right lung and pleural surface of left lower lobe of case 1 to show the extent of haemorrhage. The pale fringe at the lower edge of the left lower lobe is the only normal lung.

He received hydrocortisone $100 \mathrm{mg}$. i.v. (repeated 8.30 a.m.), ampicillin $62.5 \mathrm{mg}$., cloxacillin $62.5 \mathrm{mg}$. i.v., chloramphenicol $50 \mathrm{mg}$., and phenobarbitone grain $\frac{1}{4}$. A drip was set up and $39 \mathrm{ml}$. of fresh frozen plasma given over a period of three hours, but he continued to bleed. His temperature had fallen to $36^{\circ} \mathrm{C}$. by 8.0 a.m. Blood was taken at 9.30 a.m. from the left femoral artery (specimen A). At 10.45 a.m. the child died and blood was immediately taken by cardiac puncture (specimen B).

A necropsy was performed one and a quarter hours after death. The body was that of a pale mature child. Crown-heel measurement was $49 \mathrm{~cm}$., crown-rump $34 \mathrm{~cm}$. There were bruises at the neck and groins at the sites of needle puncture. Blood was present around the mouth and nose. Internally the respiratory passages were almost entirely filled with blood except for the anterior fringe of the lungs (Fig. 1). The left lung (all organs as fixed weights) weighed $44 \mathrm{~g}$., the right $58 \mathrm{~g}$. There were no pleural effusions. Other organs were pale in contrast. There was a little bruising in the oesophagus, behind the larynx. The liver weighed $124 \mathrm{~g}$. The brain weighed $380 \mathrm{~g}$. and was pale with no haemorrhage. The stomach was distended with air and showed a number of shallow erosions. Other organs were unremarkable.

On microscopy massive intrapulmonary haemorrhage was confirmed. The gastric erosions showed no surrounding reaction.

CASE 2 This child was born to a 23-year-old primigravida, blood group $\mathrm{O} R \mathrm{R}$ positive with negative Wassermann reaction. At the age of 20 she had an ovarian cystectomy. In the first few weeks of this pregnancy she suffered from hyperemesis. At 30 weeks' gestation she was admitted with premature rupture of the membranes. Forty-eight hours after the rupture spontaneous delivery took place,

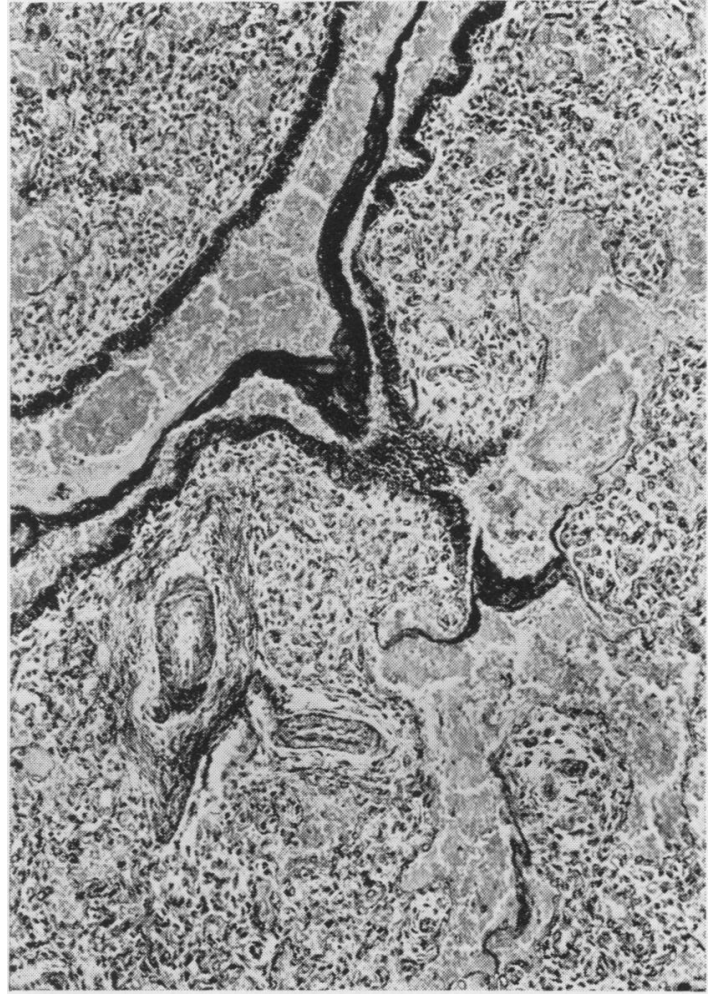

FIG. 2 Photomicrograph of the lung of case 2 to show membranes in the bronchi staining black for fibrin. Respiratory epithelium also appears dark but the haemorrhage is not well shown by this technique. Mallory's P.T.A.H. $\times$ 80.

aided by an episiotomy. Labour lasted $10 \frac{1}{2}$ hours. The placenta (425 g.) was recorded as small but healthy.

The child breathed in 30 seconds. Half an hour after birth his temperature was $35^{\circ} \mathrm{C}$. and he showed early signs of respiratory distress. He was treated with oxygen, vitamin K, $1.5 \mathrm{mg}$., and antibiotics. Over the $63 \frac{1}{2}$ hours of his life he was never well. Treatment was continued with a regime of intravenous sodium bicarbonate and dextrose. Vitamin K, $1.5 \mathrm{mg}$., was repeated on the first day. His true blood glucose level was $26 \mathrm{mg}$. \% on that day and $51 \mathrm{mg}$. $\%$ on the second, temperature $34^{\circ} \mathrm{C}$.,

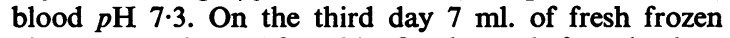
plasma was given. After this, five hours before death, a sample of blood was taken from a scalp vein for coagulation studies. A little later fresh blood poured from the larynx. His blood $p \mathrm{H}$ was $6 \cdot 0, \mathrm{pCO}_{2} 150$. He was intubated and put on intermittent positive pressure respiration but died.

A necropsy (Dr. K. M. Laurance) was performed 24 hours after death. The body was that of a premature male infant, pale and slightly icteric, with petechiae on the trunk. Weight was 1,630 g., crown-heel measurement $42 \mathrm{~cm}$., crown-rump $27 \mathrm{~cm}$. Internally the respiratory passages were extensively filled with blood. The left lung 
(fixed weights) was $20 \mathrm{~g}$., the right $25 \mathrm{~g}$. The heart and thymus showed a few petechiae. The liver weighed $53.5 \mathrm{~g}$.; the brain, $150 \mathrm{~g}$., showed bilateral intraventricular haemorrhages. There was a mild serosanguineous subdural effusion. Other organs were unremarkable.

Microscopy confirmed the massive pulmonary haemorrhage. The lungs showed extensive atelectasis and hyaline membranes were present. Some of these membranes, situated particularly in the bronchi, were positive with Mallory's phosphotungstic acid haematoxylin stain (Pearse, 1960) for fibrin (Fig. 2).

\section{LABORATORY METHODS}

Blood was collected into $3.8 \% \mathrm{w} / \mathrm{v}$ tri-sodium citrate in the proportion of 1 part of citrate to 9 parts of blood. Plasma was separated by centrifuging at 3,000 r.p.m. for 10 minutes and stored at $-20^{\circ} \mathrm{C}$. Tests were performed within 24 hours except where stated.

STANDARD COAGULATION TESTS One- and two-stage prothrombin times were performed as described by Biggs and Macfarlane (1962). The thromboplastin generation tests were performed on unadsorbed plasma as described by Hicks and Pitney (1957).

THROMBIN CLOTTING TIMES To $0.1 \mathrm{ml}$. of plasma was added $0.1 \mathrm{ml}$. of $0.85 \%$ saline and the clotting time at $37^{\circ} \mathrm{C}$. determined on the addition of $0.1 \mathrm{ml}$. of a solution of bovine thrombin (Parke Davis). The thrombin was diluted with saline so that the clotting time of normal adult plasma under the same conditions was approximately 15 seconds.

Calcium thrombin clotting times were performed as above except that the thrombin was diluted in $M / 40$ calcium chloride.

In some experiments protamine sulphate, $100 \mathrm{mg}$. per $100 \mathrm{ml}$., was substituted for the saline in the thrombin clotting time.

PLASMA FIBRINOGen This was measured as described by Varley (1960) modified as follows. Plasma, 0.2 ml., was added to $0.5 \mathrm{ml}$. of normal saline and clotted at $37^{\circ} \mathrm{C}$. with $0.1 \mathrm{ml}$. of bovine thrombin, 25 units per $\mathrm{ml}$. The fibrin was subsequently harvested and estimated as tyrosine as described by Varley (1960). In some experiments $0.1 \mathrm{ml}$. of protamine sulphate $100 \mathrm{mg}$. per $100 \mathrm{ml}$. was included with the plasma. This addition did not affect the fibrinogen value of three samples of normal adult plasma.

\section{RESULTS}

CASE 1 Two samples of blood were tested. Sample A was taken 75 minutes before death and sample B was taken by cardiac puncture immediately after death.

Thrombin clotting time tests The results of these are shown in Table I. The thrombin clotting times of both samples were grossly prolonged unless protamine was added when fine clots were formed in 16 seconds. Calcium shortened the prolonged
TABLE I

RESULTS OF THROMBIN CLOTTING TIME DETERMINATIONS으 IN CASE 1

\begin{tabular}{lrrr} 
Test & Sample $A^{1}$ & Sample $B^{2}$ & Control \\
\hline $\begin{array}{l}\text { Unmodified thrombin clotting } \\
\text { time (sec.) }\end{array}$ & over 240 & over 240 & 16 \\
$\begin{array}{l}\text { Protamine-thrombin clotting } \\
\text { time (sec.) }\end{array}$ & 16 & 16 & 7 \\
$\begin{array}{c}\text { Calcium-thrombin clotting } \\
\text { time (sec.) }\end{array}$ & - & 120 & 15
\end{tabular}

'Sample A was taken before death.

'Sample B was taken at death.

thrombin clotting time of sample B but this was still very abnormal. Thrombin clotting times (without calcium) were also performed on mixtures of $\overrightarrow{0}$ sample B with normal plasma in varying proportions. The results are shown in Table II. A weak inhibitory $\omega$ effect on the thrombin-fibrinogen reaction of adult plasma is shown.

\section{TABLE II}

THROMBIN CLOTTING TIMES OF MIXTURES OF NORMAL ANDEO PATIENT'S PLASMA (SAMPLE B) IN CASE 1

$\begin{array}{lrrrrr}\text { Parts normal plasma } & 10 & 8 & 5 & 2 & 0 \\ \begin{array}{l}\text { Parts sample B } \\ \begin{array}{l}\text { Thrombin clotting time } \\ \text { (sec.) }\end{array}\end{array} & 0 & 2 & 5 & 8 & 10 \\ & 15 & 15 & 19 & 30 & 240\end{array}$

Plasma fibrinogen Initial attempts to assayo plasma fibrinogen with thrombin alone were un- $\overrightarrow{\vec{T}}$ satisfactory because the plasma would not readily 3 clot. Highest values were obtained when $0.1 \mathrm{ml}$. of protamine sulphate was added to the assay mixture on samples stored for seven weeks at $-20^{\circ} \mathrm{C}$. Ther $128 \mathrm{mg}$. of fibrinogen per $100 \mathrm{ml}$. was detected in sample $A$ and $78 \mathrm{mg}$. in sample $B$.

Thromboplastin generation test Thromboplastin generation in both samples was grossly defective (Table III). Mixtures of patient's plasma with various proportions of normal plasma were made and thromboplastin generation tests performed on each mixture. The results, also shown in Table III, indicate that a potent inhibitor of thromboplastinf generation was present in sample B but this was not so obvious in sample A. Insufficient of the latter sample was available to justify further attempts to detect inhibition.

\section{TABLE III}

THROMBOPLASTIN GENERATION TESTS IN PATIENT'S PLASMAT AND IN MIXTURES WITH NORMAL PLASMA IN CASE 1

Parts normal plasma

Parts patient's plasma

Substrate clotting time (sec.) after

6 min. incubation (sample A)

Substrate clotting time (sec.) after

$6 \mathrm{~min}$. incubation (sample B)

$\begin{array}{rrrrr}10 & 8 & 5 & 2 & 0 \\ 0 & 2 & 5 & 8 & 10 \\ 10 & 10 & 10 & 27 & 69 \\ 10 & 55 & 42 & 87 & 79\end{array}$


In summary the coagulation defect in this patient's plasma consisted of a reduced level of fibrinogen, prolonged thrombin clotting time corrected by protamine, and defective thromboplastin generation.

CASE 2 The blood from this infant was collected five hours before death and only a very small amount of plasma was available for study.

Standard coagulation tests The results of thrombin clotting times, one-stage prothrombin times, and two-stage prothrombin assays are shown in Table IV.

TABLE IV

RESULTS OF STANDARD COAGULATION TESTS IN CASE 2

Test Patient $\begin{aligned} & \text { Normal Range or } \\ & \text { Control Values }\end{aligned}$

\begin{tabular}{lrc}
\hline Thrombin clotting time (sec.) & 31 & 15 \\
Thrombin-protamine clotting time (sec.) & 8 & 7 \\
Thrombin-calcium clotting time (sec.) & 22 & 13 \\
One-stage prothrombin time (sec.) & 18 & $11 \cdot 5$ \\
Two-stage prothrombin $(\%)$ & 34 & $60-120$ \\
Plasma fibrinogen (mg. $/ 100 \mathrm{ml}$.) & 213 & $200-400$
\end{tabular}

The thrombin clotting times both with and without calcium were slightly prolonged as compared to normal adult plasma, but were within the normal range for neonates (Roberts, Gray, and Bloom, 1966). There was moderate prolongation of the onestage prothrombin time and mild deficiency of prothrombin. The clots in these tests were of normal appearance and the plasma fibrinogen level was $213 \mathrm{mg} . / 100 \mathrm{ml}$.

Thromboplastin generation test Thromboplastin generation was grossly abnormal (Table V) and the patient's plasma failed to correct the defect present in both severe factor VIII-deficient (haemophilic) and factor IX-deficient (Christmas disease) plasma. The results of mixing experiments with normal plasma are also shown in the table and suggest the presence of an inhibitor of thromboplastin formation. Thus two parts in 10 of normal plasma failed to correct the patient's plasma, and two parts of patient's plasma slightly impaired thromboplastin generation in normal plasma.

In summary the coagulation defect in this patient's plasma consisted of a moderate prolongation of the

TABLE V

THROMBOPLASTIN GENERATION IN PATIENT'S PLASMA AND IN MIXTURES WITH NORMAL, FACTOR VIII- AND FACTOR IX-DEFICIENT PLASMA IN CASE 2

\begin{tabular}{|c|c|c|c|c|c|c|c|c|c|}
\hline $\begin{array}{l}\text { Parts normal plasma } \\
\text { Parts factor VIII-deficient }\end{array}$ & 10 & - & 2 & - & - & 2 & - & 2 & \\
\hline $\begin{array}{l}\text { plas } \\
\text { Parts }\end{array}$ & - & 10 & 8 & 8 & - & - & - & - & \\
\hline & - & - & & & 10 & 8 & 8 & - & \\
\hline $\begin{array}{l}\text { Parts patient's plasma } \\
\text { Substrate clotting time after }\end{array}$ & - & - & - & 2 & - & - & 2 & 8 & \\
\hline & 7 & 51 & & & 52 & 8 & 65 & 57 & \\
\hline
\end{tabular}

one-stage prothrombin time and reduction of prothrombin, but a severe defect of thromboplastin generation was associated with the presence of an inhibitor.

\section{DISCUSSION}

Surveys of fibrinogen values in the newborn show that they are a little lower than in the adult (Taylor, 1957). However, de Souza, Ferreira, Gomes, and Estrela (1953), using a calcium clotting method, found four values of $50 \mathrm{mg}$. per $100 \mathrm{ml}$. in 50 newborn infants, none of whom showed abnormal bleeding. Hartmann, Howell, and Diamond (1955) refer briefly to two cases. In one there was sepsis with severe liver damage and multiple coagulation defects, including a low fibrinogen value, but in the other hypofibrinogenaemia was associated with active fibrinolysis. Valentine (1958) described a child of a mother who had antepartum haemorrhage, hypofibrinogenaemia, and accelerated fibrinolysis. The child's initial fibrinogen level (as measured by a thrombin clotting time method) was $7.5 \mathrm{mg} . / 100 \mathrm{ml}$. and fibrinolysis was increased. The child survived but with evidence of cerebral damage. ReerinkBrongers and De Koningh (1964) also found a low plasma fibrinogen level, $55 \mathrm{mg} . / 100 \mathrm{ml}$., in a child with suspected cerebral haemorrhage.

Assay values of clottable fibrinogen can sometimes be increased by adding protamine to the plasma. Such was the situation in case 1 of the present study. While the distinction by this means between true and apparent hypofibrinogenaemia may reflect some difference in pathogenesis, the amount of fibrinogen capable of clotting normally in unmodified plasma is likely to be the important factor in maintaining haemostasis.

A prolonged thrombin clotting time may be caused by lack of fibrinogen. The fact that protamine caused considerable reduction of this time, however, suggests that in our case another factor is involved. Prolongation of the thrombin-fibrinogen reaction usually develops during active fibrinolysis and fibrinogenolysis (Fletcher, Alkjaersig, and Sherry, 1962). A similar phenomenon previously reported by Niewiarowski and Kowalski (1958) was reversed by protamine. An inhibitor of thromboplastin generation may also develop during fibrinogenolysis (Niewiarowski, Latallo, and Stachurska, 1959). Studies of the fibrinolytic system were not performed in our cases but the presence of abnormalities, particularly in case 1 , which could result from activation of this system, suggests that this may be concerned in the pathogenesis of the coagulation defects observed. Possibly fibrinogen breakdown products inhibit the generation of thromboplastin and prevent normal fibrin polymerization. 
Prolongation of the thrombin clotting time reversible by protamine sometimes accompanies the obstetric defibrination syndrome (Bloom and Campbell, 1965). The change seen in case 1 may therefore represent the defibrination syndrome of the newborn. Boyd (1965) has postulated a similar condition in the newborn on the basis of fibrin thromboembolism which he describes in the vessels as seen in histological section from necropsy material. One of us has observed similar deposits in a newborn child dying with severe haemorrhage. In the present study we found no such evidence of intravascular coagulation but these deposits may be labile and easily lysed.

The coagulation defects in case 2 do not particularly suggest hyperactive fibrinolysis. Although an inhibitor of thromboplastin generation may develop in this state there was no other supportive evidence and the fibrinogen level was normal. The prematurity of the infant may have contributed to some of the coagulation factor deficiencies but the cause of the inhibitor is not known.

No causal relationship between the presence of massive pulmonary haemorrhage and the severe coagulation defects described has been shown in the present study. However Cain and Crane (1965) also described a child with massive pulmonary haemorrhage whose blood would not clot on the addition of thrombin. Severe umbilical bleeding had preceded the test and there was evidence for increased fibrinolysis. Our observation of a grossly prolonged thrombin clotting time in the blood of apparently normal newborn infants (Roberts et al., 1966) suggests that these changes may not merely be terminal events in severely ill children. It is also unlikely that the infusions of fresh frozen plasma given to our patients contributed to the defect. These have never been seen in patients similarly treated for other disorders. Further studies correlating the coagulation and fibrinolytic systems in normal and affected newborn infants may show if bleeding is related to sueh defects as those we describe.

We would like to acknowledge the generous help gifen by Dr. O. P. Gray, who made the clinical diagnosis these two cases, also the cooperation of Dr. K. 1 . Laurance. Professor Jethro Gough kindly gave advice. $\mathbb{\complement}$

\section{REFERENCES}

Ahvenainen, E. K., and Call, J. D. (1952). Amer. J. Path., 28, 1. Biggs, R., and Macfarlane, R. G. (1962). Human Blood Coagulatign, and its Disorders, 3rd ed. Blackwell Scientific Publicatiogs, Oxford.

Bloom, A. L., and Campbell, N. (1965). J. clin. Path., 18, 786.

Boyd, J. F. (1965). J. Path. Bact., 90, 53.

Butler, N. R., and Bonham, D. G. (1963). Perinatal Mortality. The First Report of the 1958 British Perinatal Mortality Surtey, p. 263. Livingstone, Edinburgh and London.

Cain, A. R. R., and Crane, G. A. (1965). Lancet, 2, 690.

Claireaux, A. E. (1958). In Modern Trends in Paediatrics, 2nd ser. edited by A. Holzel and J. P. M. Tizard, p. 54. Butterworth, London.

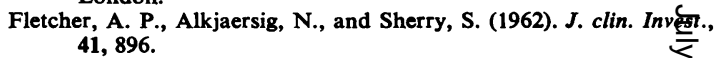

Hartmann, J. R., Howell, D. A., and Diamond, L. K. (1955). Amer. J. Dis. Child., 90, 594.

Hicks, N. D., and Pitney, W. R. (1957). Brit. J. Haemat., 3, 227.

MacGregor, A. R. (1960). Pathology of Infancy and Childhood, p. 54 Livingstone, Edinburgh and London.

Mann, T. P., and Elliott, R. I. K. (1957). Lancet, 1, 229.

Niewiarowski, S., and Kowalski, E. (1958). Rev. Hémat., 13, 320.

-, Latallo, Z., and Stachurska, J. (1959). Sang, 30, 376.

Pearse, A. G. E. (1960). Histochemistry; Theoretical and Applied, and ed., p. 818. Churchill, London.

Potter, E. L. (1961). Pathology of the Fetus and Infant, 2nd ed. \$ar

Book Medical Publishers, Chicago.
Reerink-Brongers, E. E., and De Koningh, M. J. (1964). Lance올, 985.

Roberts, J. T., Gray, O. P., and Bloom, A. L. (1966). Acta paedint. (Uppsala), 55, 148.

Sivanesan, S. (1961). J. Pediat., 59, 600.

de Souza, C. S., Ferreira, J. C., Gomes, A. F., and Estrela, A. (19:33). Arch. franc. Pédiat., 10, 474.

Taylor, P. M. (1957). Pediatrics, 19, 233.

Thorburn, M. J. (1963). Arch. Dis. Childh., 38, 589.

Valentine, G. H. (1958). Obstet. and Gynec., 12, 462.

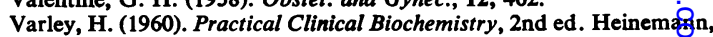
London.

Vejlens, G. (1944). Acta path. microbiol. scand., suppl. 54.

(1)

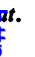
(a) a

$$
\text { 醇 }
$$
, 